\title{
Entre la emancipación y la captura: autonomización de la palabra y resistencia a las necropolíticas en los territorios indígenas nasa
} (Colombia)

Between emancipation and capture: autonomization of the words and resistance to necropolitics in Nasa Territory (Colombia)

\author{
Simone Ferrari \\ Università degli Studi di Milano, Milán, Italia \\ Pontificia Universidad Javeriana, Bogotá D. C., Colombia \\ https://orcid.org/0000-0002-3339-5737
}

Artículo de reflexión

Fecha de recepción: 31 de diciembre de 2018

Fecha de aceptación: 25 de abril de 2019

\section{Para citar este artículo}

Ferrari, S. (2019). Entre la emancipación y la captura: autonomización de la palabra y resistencia a las necropolíticas en los territorios indígenas nasa (Colombia). Campos en Ciencias Sociales, 7(2), 125-146. DOI: https://doi. org/10.15332/25006681.5019

1. Estudiante de Doctorado en Estudios Lingüísticos, Literarios e Interculturales de la Università degli Studi di Milano, Milán, Italia. Estudiante de Doctorado en Ciencias Sociales y Humanas de la Pontificia Universidad Javeriana, Bogotá D. C., Colombia. Correo electrónico: simone.ferrari1@unimi.it 


\section{Resumen}

En el proceso de construcción de la categoría de ciudadano en Colombia han primado prácticas constitutivas excluyentes, fundadas en una división sistemática entre individuos considerados dignos de ser ciudadanos e homines sacri (Agamben), es decir, hombres marginados y sacrificables. Dichas prácticas han contribuido a la formación de espacios de tolerancia de dinámicas de dominación necropolítica (Mbembe). El nororiente del Cauca es un caso de territorio en donde se ha sido permitido un ejercicio constante de necropolíticas, manifestadas tanto en el actuar de los centros de poder como en sus construcciones discursivas. Sin embargo, en una región históricamente capaz de generar epicentros de resistencias, ¿las comunidades locales se piensan en tanto marginadas?, ¿cuáles imaginarios de disidencia se están produciendo en el territorio? La propuesta del presente artículo se orientó a la indagación de las respuestas más actuales que se están elaborando en la comunidad nasa del Cauca. El proceso investigativo se centró en el análisis de la configuración y del uso de nuevas prácticas discursivas en el texto Entre la emancipación y la captura (2017) de la escritora Vilma Almendra, quien, a través de un trabajo de textura de voces comunitarias, se propuso replicar a las marginalizaciones impuestas por medio de un replantamiento descolonizador de la función de la palabra, con el fin de proteger el "territorio del imaginario" de las intervenciones estatales.

Palabras clave: comunidad nasa, necrolenguaje, palabrandar, resistencia indígena, Vilma Almendra.

\section{Abstract}

In the process of construction of the category citizen in Colombia, there have been carried out dynamics of exclusion, started from a systematic division between individuals considered worthy of being citizens and homines sacri, (Agamben) marginalized and sacrificable people. This process has contributed to the formation of intra-national territorial borders in which is tolerated the use of necropolitic practices. The northeastern region of Cauca is an example of a territory where a constant exercise of necropolitics has been allowed. Nevertheless, in a region historically capable of generating epicenters of resistance to exclusion or forced inclusion, do local communities think of themselves as marginalized? What kind of dissident imaginaries are taking place in the territory? The proposal of this article was oriented to the 
investigation of the latest responses that are being elaborated by Nasa people in northeastern region of Cauca. The core of the research process focused on the analysis of the configuration and use of new discursive practices in the text Entre la emancipación y la captura (2017) by Nasa-misak writer Vilma Almendra, which, through a texture work of community voices, aims to replicate the marginalization imposed by the centers of power through a decolonizing rethinking of the function of the word, a in order to protect the "imaginary territory" of state interventions.

Keywords: Necrolanguage, indigenous resistance, Nasa community, palabrandar, Vilma Almendra.

\section{INTRODUCCIÓN Y METODOLOGÍA}

\section{Necropolíticas y marginación en el norte del Cauca}

Al definir la noción de necropolítica, el filósofo camerunés Achille Mbembe (2006) se mueve a partir del concepto foucaultiano de biopoder, entendido como "el viejo derecho soberano de matar" (Foucault, 1992, p. 90), para identificar las violencias estructurales de los sistemas de dominación contemporáneos en ciertas regiones del denominado sur global, donde la soberanía se expresa y representa en torno a la "capacidad de decidir quién puede vivir y quién debe morir" (Mbembe, 2006, p. 11): si con el surgimiento de los Estados modernos la violencia había representado un medio "para lograr la rentabilidad" (p. 14), en época poscolonial, según el pensador africano, esa violencia se ha convertido en un objetivo. Las formas de control poblacional ejercidas bajo la necropolítica, definidas en su conjunto como necropoder, se presentan como una etapa sucesora del biopoder foucaultiano, en un giro conceptual identificable temporalmente en el periodo colonial, "momento de gran desestructuración de los límites entre la vida y la muerte que propició el silenciamiento del cuerpo" (p. 14), en el que se engendran formas de poder difuso -no exclusivamente estatal- fundadas en la "economía de la muerte" (2006, p. 14), es decir, en el control absoluto del derecho a la vida del gobernado. 
Si bien el trabajo de Mbembe se contextualiza desde lugares de enunciación y topografías específicas (conflicto palestino, apartheid en Sudáfrica, guerra del Golfo, campaña contra Kosovo) ${ }^{2}$, en las formas de manifestación de las políticas de la muerte enunciadas por el autor camerunés se evidencian diferentes rasgos que se corresponden con prácticas comunes en espacios excluyentes propios de geografías otras, localizadas de igual forma en territorios que el experto brasileño Leomir Cardoso Hilário define como "periferia do capitalismo" (2016); en este sentido, son diferentes los estudios que aplican la categoría de necropolítica a distintos (y muy variados entre ellos) contextos de marginación socioespacial en América Latina, como las periferias afrobrasileñas de São Paulo (Alves, 2011), las cárceles colombianas (Bello y Parra, 2016), las fronteras migratorias entre Estados Unidos y México (Estévez, 2018) o la represión policial de los espacios de protesta en Venezuela (Ávila, 2018) ${ }^{3}$. Un atento análisis de la propuesta de Achille Mbembe permite ubicar otro espacio de manifestación del necropoder en el contexto específico analizado en este artículo: el conflicto por la tierra en la región del norte del Cauca (Colombia), donde las comunidades indígenas nasa ${ }^{4}$ llevan siglos revindicando el derecho a la propiedad colectiva y a la autonomía de los territorios ancestrales, ante los intentos de conquista y explotación impulsados por el Gobierno colombiano, por élites locales y transnacionales y por diferentes actores armados ilegales.

Entre los mecanismos de necropoder que señala Mbembe y que corresponden con ejercicios de dominación comunes en el departamento del Cauca, se encuentran:

2. Además de profundizar los contextos nacionales señalados, Mbembe se centra en algunos rasgos comunes de la etapa poscolonial de la historia continental africana, en particular en su análisis del desarrollo de ciertas dinámicas económicas, políticas y militares de los siglos XX y XXI. Se deja aquí de lado el aspecto económico de la teorización de Mbembe, que poco se relaciona con el contexto específico presentado en el artículo, para focalizarse en las prácticas de dominación y en las manifestaciones militares del necropoder en el "locus poscolonial”. (Mbembe, 2006, p. 14).

3. Como referencia general para la teorización de la aplicabilidad de la categoría de necropolítica en contextos latinoamericanos, se remite a Fuentes Díaz (2012).

4. De las numerosas comunidades indígenas presentes en el Cauca (que representan el $21 \%$ de la población del departamento), los nasa son el grupo más numeroso (alrededor de 140000 personas), en particular en el norte de la región, representando el $60 \%$ de la población indígena caucana, en un territorio que cuenta con una totalidad de ocho etnias (nasa, guambianos, yanaconas, coconucos, emberas, totoroes, ingas y guanacos). (Peñaranda Supelano, 2012, p. 13). 
1. La participación en un conflicto de ejércitos privados/ilegales, con la consiguiente pérdida del monopolio de la violencia por parte del Estado, que se convierte en una de las variadas "máquinas de guerra"5 que actúan en el territorio (Mbembe, 2006, p. 58): en el caso caucano, una cantidad muy relevante de actores armados no regulares se encuentran radicados en la región desde la primera mitad del siglo XX, ejerciendo diferentes prácticas de dominación e imposición violenta de control territorial y desarrollando conexiones e interrelaciones con los actores estatales.

2. Un sistema de guerra de baja intensidad relacionado con la explotación del territorio para la extracción de recursos naturales, con el objetivo de crear "mecanismos depredadores extremamente organizados, que aplican tasas en los territorios y las poblaciones que ocupan y cuentan con el apoyo, a la vez material y financiero, de redes transnacionales y de diásporas" (Mbembe, 2006, p. 54): un ejercicio de poder presente en el suroccidente colombiano tanto en términos de minería ilegal como, en forma aún más extensa, en el aprovechamiento de cultivos ilícitos de marihuana y coca ${ }^{6}$.

3. Una fragmentación territorial, social, económica y política promovida por el Estado, a través del impulso de conflictos internos: un proceso bien conocido en el departamento del Cauca, donde la implementación de planes políticos

5. Mbembe retoma aquí el concepto propuesto por Deleuze y Guattari (1980) para identificar las dinámicas entre actores armados y Estado en algunos países de África: "Organizaciones difusas y polimorfas, las máquinas de guerra se caracterizan por su capacidad para la metamorfosis. Su relación con el espacio es móvil. Algunas veces mantienen relaciones complejas con las formas estatales (que pueden ir de la autonomía a la incorporación). El Estado puede, por sí mismo, transformarse en una máquina de guerra. Puede, por otra parte, apropiarse para sí de una máquina de guerra ya existente, o ayudar a crear una. Las máquinas de guerra funcionan tomando prestado de los ejércitos habituales, aunque incorporan nuevos elementos bien adaptados al principio de segmentación y de desterritorialización. Los ejércitos habituales, por su parte, pueden apropiarse fácilmente de ciertas características de las máquinas de guerra”. (Mbembe, 2006, pp. 58-59).

6. La problemática de los cultivos ilícitos, surgida en el Cauca en los ańos setenta del siglo XX, se ha intensificado a partir de las dos décadas sucesivas; en la etapa actual de la lucha indígena nasa en el norte del Cauca han asumido un papel clave temáticas como la erradicación y sustitución de cultivos ilícitos y las resistencias comunitarias a los intentos de control y explotación de territorios y cuerpos por parte de grupos armados conectados con el narcotráfico, dentro de un sistema de dominación extremamente radicado en la región que ha convertido el mercado de las drogas en un brazo armado del necropoder. Por lo que concierne a la relación entre poder y narcotráfico en América Latina, ver a Valencia Triana (2017). 
nacionales tales como el Tratado de Libre Comercio con Estados Unidos, el Plan Colombia o la política de seguridad democrática, han engendrado dinámicas violentas de división y tensión internas en la región.

4. La utilización de estrategias de destrucción de los cuerpos y de máquinas de terror que impliquen que "los cuerpos sin vida" sean "rápidamente reducidos al estatus de simples esqueletos [...] reliquias de un duelo perpetuo, corporalidades vacías, desprovistas de sentido, formas extrañas sumergidas en el estupor" (Mbembe, 2006, p. 64). Episodios tales como la masacre de Caloto (16 de diciembre de 1991), donde miembros de la Policía Nacional de Colombia, en una operación conjunta con actores armados ilegales, asesinaron a 21 indígenas nasa durante la ocupación pacífica de la finca El Nilo, han cubierto la historia reciente de la región del suroccidente colombiano, hasta llegar a las matanzas de líderes sociales de los años más recientes (de los 295 líderes asesinados en Colombia entre diciembre de 2016 y julio de 2018, 56 han sido asesinados en el departamento del $\mathrm{Cauca}^{7}$ ), en una serie inacabada de violencias que se benefician del miedo generalizado para privatizar cuerpos y territorios.

Ahora bien, estas políticas de muerte generarían, según Mbembe, la difusión entre las poblaciones víctimas, de una condición de existencia social de "muertos-vivientes": una marginalización impuesta que se funda, ante todo, en la sustracción del derecho a la vida y, consecuentemente, en una limitación del sujeto, reducido, en términos del filósofo italiano Giorgio Agamben, a homo sacer: "aquel a quien el pueblo ha juzgado por un delito; no es lícito sacrificarle, pero quien le mate, no será condenado por homicidio" (Agamben, 1998, p. 94). Al señalar la pertinencia de la categoría en la modernidad, Agamben detalla la relevancia del carácter de marginación del sujeto, convertido en objeto de prácticas de exclusión impuestas, segregado a un estado, en términos foucaultianos, de "aceptabilidad de la matanza" (Foucault, 1992, p. 10). El pensador italiano conceptualiza dicha condición como la "nuda vida", es

7. El Cauca es el departamento colombiano que ha contado con más asesinatos de líderes sociales desde la firma de los acuerdos de paz; aquí los datos recogidos desde diciembre de 2016 hasta julio de 2018: <eltiempo.com/ colombia/otras-ciudades/el-mapa-de-los-lideres-sociales-asesinados-en-colombia-184408> consultado el 8 de octubre de 2018. 
decir, "el singular privilegio de ser aquello sobre cuya exclusión se funda la ciudad de los hombres" (Agamben, 2002, p. 17). Una condición al mismo tiempo corporal (individual) y espacial (colectiva), porque el estado del homo sacer se pluraliza en la creación de territorios de exclusiones, que Mbembe denomina como "mundos de muerte", o "formas únicas y nuevas de existencia social en las que numerosas poblaciones se ven sometidas a condiciones de existencia que les confieren el estatus de muertos-vivientes" (Mbembe, 2006, p. 75). Con todo, y para matizar la lógica argumental y aterrizar las reflexiones teóricas al caso de los indígenas en lucha por la tierra en el Cauca: a pesar de la evidencia y de la constancia de las necroprácticas que los pueblos nativos del territorio sufren hace más de cinco siglos, ¿es legítimo pensar en estas poblaciones (y en estos espacios) como en sujetos al margen (muertos-vivientes, homines sacri) a la luz de las imponentes resistencias y disidencias que se generan y que se siguen practicando en la región? ¿Los mismos indígenas nasa se piensan como sujetos marginados? ¿Qué tipo de lecturas y qué tipo de respuestas plantean a las opresiones gubernativas y transnacionales en la actualidad? La propuesta que se presenta aquí intenta acercarse a estas preguntas por medio de una mirada focalizada en las soluciones que se están generando a partir de ciertas tendencias a la valoración de la palabra escrita tejidas desde la comunidad nasa, en particular a través de una obra de extrema relevancia dentro de las más contemporáneas narrativas autorrepresentacionales en el contexto de las luchas caucanas para la defensa de la autonomía del territorio: Entre la emancipación y la captura. Memorias y caminos desde la lucha nasa en Colombia (2017a), escrita -en un proceso de constante diálogo colectivo comunitario- por la pensadora nasa-misak Vilma Almendra. El análisis se realizó mediante un enfoque en el valor performativo de la palabra escrita, interpretada como herramienta catalizadora de la construcción de los imaginarios de lucha nasa: a través de una profundización de las prácticas semióticas propuestas en el texto, se intentaron descifrar las innovaciones de Almendra en la construcción de un lenguaje resistente, autónomo y comunitario, capaz de posicionarse en contraposición a los modos discursivos propios de los necropoderes que actúan en la región.

\section{Nuevos tejidos de resistencia nasa: los desafíos de la palabra}

La historia de resistencias de los pueblos indígenas nasa en la región del norte del Cauca tiene aliento plurisecular, y el extraordinario trabajo de reconstrucción y 
textura de mitos e identidades de resistencia, impulsado en las últimas cinco décadas por organizaciones locales como el Consejo Regional Indígena del Cauca (CRIC) ${ }^{8}$, da cuenta de ciertas constancias y ciclicidades en los cinco siglos de lucha para la defensa y la autonomía de territorios y cuerpos, víctimas de perennes ataques por parte de los diferentes brazos armados y explotadores de las "máquinas antropológicas" (Agamben, 2006, p. 63) (neo)coloniales que se sucedieron desde la conquista. Las narrativas de resistencia tejidas desde las comunidades nasa del Cauca durante los últimos 50 años se reconstruyen a partir de tres personajes históricos fundacionales que articulan la genealogía de la lucha caucana: la cacica Gaitana, Juan Tama de la Estrella y Manuel Quintín Lame', a los cuales se añadió en época reciente la figura del padre Álvaro Ulcué Chocué ${ }^{10}$. En un denso trabajo de textura de las simbologías, los mitos, las herencias orales y escritas conectadas con las cuatro identidades clave en el imaginario de resistencia indígena, la cacica Gaitana, Juan Tama, Quintín Lame y el padre Ulcué, se han convertido en espejos para los nuevos derroteros de pensamiento y acción de luchas territoriales; estos actos de rememoración abren espacio a una concepción de la resistencia nasa en el Cauca como una estructura cíclica y capaz de autorreproducirse y reconformarse según las épocas, lo cual está permitiendo la activación de una "memoria cultural", en el sentido que le atribuye Eric Wolf (1972) y que retoma Peñaranda Supelano en su estudio sobre el Movimiento Armado

8. Este proceso de revitalización cultural y de motivación de la memoria para reconstruir la historia se construye a partir de un entretejido entre el actuar político, comunicativo y educativo, como lo señala el mismo CRIC, quien se mueve en esta dirección desde su surgimiento en 1971: "En el CRIC, la educación es hacer política y en política es hacer educación. Por lo tanto, su programa de educación bilingüe e intercultural (PEBI) contribuye directamente a los objetivos fundamentales de la organización: unidad, tierra, cultura y autonomía” (Consejo Regional Indígena del Cauca, 2004). En este sentido, la construcción de la memoria de resistencia encuentra un fundamental espacio de desarrollo en las escuelas.

9. Aun perteneciendo a épocas distintas, la cacica Gaitana, Juan Tama de la Estrella y Manuel Quintín Lame se asocian, en la periodización -conceptual y no solamente cronológica- de la historia nasa propuesta por el tejido de comunicación de la ACIN, a una misma etapa de la historia comunitaria definida como "etapa de resistencia", cuyo comienzo se adscribe a la invasión española, y cuya conclusión se asocia al "despertar de las consciencias" (Almendra, 2017a, p. 85) de las comunidades indígenas impulsada por las acciones y las enseńanzas de Manuel Quintín Lame.

10. Primer sacerdote católico indígena en Colombia, asesinado en 1984 por dos sicarios, el padre Álvaro Ulcué Chocué sigue siendo una figura de relevancia absoluta en los imaginarios y en los pensamientos de la resistencia indígena caucana. En la citada periodización de la historia nasa propuesta por el ACIN, Alvaro Ulcué Chocué es protagonista de la tercera etapa, la de la "autonomía”. Además de las enormes luchas para la recuperación de tierras, Ulcué fundó e impulsó distintos proyectos para la defensa y la difusión de la cultura y de la autonomía en los territorios nasa de Toribío, Tacueyó y San Francisco. 
Quintín Lame, para definir aquel conjunto de "experiencias históricas que marcan la forma y el significado del presente de cada comunidad y que permanecen latentes hasta cuando una circunstancia política o un nuevo acontecimiento histórico configuran un escenario que les permite manifestarse con todo su vigor" (Peñaranda Supelano, 2015, p. 43).

Al hacer referencia a la memoria histórica y a la ciclicidad de la resistencia nasa, cabe subrayar la relevancia de las categorías interpretativas comunitarias locales particularmente en la conceptualización de las cronologías-. En este sentido, la lectura de las diferentes etapas de la historia indígena en el Cauca propuesta desde el tejido de comunicación de la ACIN -Asociación de Cabildos Indígenas del Norte del Cauca-y presentada en el texto Entre la emancipación y la captura de Vilma Almendra, resulta aclaradora: si bien se señalan antecedentes específicos y figuras concretas del proceso de resistencia nasa, la perspectiva epistemológica adoptada convoca una visión temporal no lineal, tejida por medio de una dialéctica entre rupturas y nuevos horizontes de luchas, a partir de la cual se identifican cuatro etapas dominantes:

La etapa de la resistencia, liderada por la cacica Gaitana en el siglo XVI con la lucha armada (conquista espańola), por Juan Tama y Manuel de Quilos -ciclos en el siglo XVII a través de la negociación (colonia española) y por Manuel Quintín Lame en los siglos XIX y XX con el despertar de la consciencia y las acciones de hecho (período republicano). La etapa de recuperación reconocida por las tomas de tierras lideradas entre indígenas y campesinos con el lema "Tierra para la gente" y el nacimiento del Consejo Regional Indígena del Cauca - CRIC el 24 de febrero de 1971, logrando una de las reformas agrarias más reconocidas en América Latina y la más grande en la historia de Colombia. La etapa de la autonomía, motivada por el padre Álvaro Ulcué Chocué desde Toribío, Cauca, en la década de los 80, con la creación de los proyectos comunitarios en la zona norte del Cauca, sigue siendo una de las experiencias prácticas. La etapa de la alternativa, sembrada desde el Congreso Indígena y Popular realizado en el 2004 cuando cerca de 60 mil personas principalmente indígenas del Cauca caminamos hacia Cali, llamando a la unidad de los pueblos para rechazar la agresión sistemática a través del TLC 
con EE. UU., la reforma constitucional y para reclamar el respeto a la vida. (Almendra, 2017a, pp. 85-86)

Dentro de esta clave exegética que identifica en resistencia, recuperación, autonomía y alternativa las cuatro constantes de la lucha nasa, desde la segunda mitad del siglo XX un nuevo medio asume un rol catalizador: la escritura en idioma espańol. La relación estricta entre proyectos culturales, educativos, escolásticos y políticos del CRIC, que progresivamente se convierte en una voz determinante en la comunicación de las exigencias indígenas - no solo caucanas, sino también nacionales y continentalesse alimenta mediante la difusión tanto oral como escrita de historias y mitos de resistencia, con el apoyo de medios como panfletos, periódicos y radio. Los contenidos de referencia se apoyan fundamentalmente en la obra de los dos mayores pensadores nasa del siglo XX: Manuel Quintín Lame y Álvaro Ulcué Chocué. Si por un lado, la obra Los pensamientos del indio que se educó en la selva (Gnecco, 2004) de Quintín Lame, conjunto de reflexiones publicadas por primera vez en el ańo del surgimiento del CRIC, impulsa la teorización de las reivindicaciones para la tierra y como lo señala Patińo Prieto "un paradigma que sirva para la construcción de una identidad indígena respetada y valorada" (2008), aun más relevancia adquieren los escritos -y las transcripciones de comunicaciones, entrevistas, intervenciones en asambleas- del padre Álvaro Ulcué Chocué, en particular después del 10 de noviembre de 1984, fecha de su asesinato. La palabra de Ulcué, profunda y cautivante, se hereda en los territorios del norte del Cauca como derrotero necesario y dinamizador de la lucha indígena, que el sacerdote nasa redibuja asignándole objetivos claros y significando las acciones, como revela, por ejemplo, el escrito de presentación de los propósitos del proyecto "Centro Indigenista Toribío Cauca":

Motivar y ayudar a descubrir la expresión cultural propia, para que valorándola se rescate la identidad y se reclamen los derechos, llevando a la práctica el mensaje de Cristo pobre que lucha con los paeces y colonos para liberarnos de la injusticia. [...] Despertar y dinamizar las fuerzas vivas existentes: cabildos, animadores de la comunidad, educadores y otros promotores de desarrollo, para que analizando juntos las dificultades, así mismo, se busquen las soluciones requeridas. (Ulcué, 1983). 
La significativa huella dejada por los dos autores en el proceso de construcción de memorias e historia, pero también en la búsqueda de sentidos, de recorridos y de destinos para alcanzar dentro del proceso de lucha nasa, profundamente influenciado por interferencias teológicas católicas en una dialéctica constante -y problematizada desde algunas voces comunitarias ${ }^{11}$ - con la cosmovisión y la teogonía ancestrales, resulta esencial tanto para la revitalización de la memoria cultural nasa como para la constitución de una nueva forma de pensar y pensarse desde lo nasa dentro de la resistencia: la palabra escrita.

Inscrita en este proceso contradictorio, azaroso, heterogéneo y disruptivo, y paralelamente a los dramáticos desarrollos del conflicto para la tierra en la región del norte del Cauca en las últimas décadas, se ubica la obra Entre la emancipación y la captura. Memorias y caminos desde la lucha nasa en Colombia (2017), surgida en los años más recientes desde la voz nasa-misak de Vilma Almendra -o desde el conjunto de voces que la autora hila: un texto que, en su posicionamiento incómodo y periférico hasta dentro de la misma comunidad, al focalizarse en las últimas etapas de los procesos de resistencia del territorio emerge como tejido fundamental para la activación y la dinamización de las latencias de las luchas y para la resignificación de la memoria cultural o "memoria vital" (Almendra, 2017a, p. 49) en palabras de la autora, de la resistencia caucana-.

\section{Palabrandar con cuerpos y territorios: resistencias a los "necrolengua- jes" de poder}

En una apuesta de extrema valentía, Vilma Almendra desdibuja y recoloca la concepción de palabra escrita, cargándola de performatividad, comunidad, cuerpo y territorio, en una profunda narración de las trayectorias, los recorridos, las tensiones y las debilidades de los años más recientes de la lucha nasa para la defensa

11. Así el padre Ezio Roattino, sacerdote de Toribío en la actualidad y presente en el territorio en los últimos años de vida de Álvaro Ulcué, recuerda ciertas tensiones entre este y miembros del CRIC: "Por parte del CRIC siempre hubo esta idea de que no había que confiar en la Iglesia. Recuerdo que no dejaron entrar a Álvaro en un congreso del CRIC. Dijeron "tú eres cura, no eres indio". Álvaro aceptó. Álvaro recibía golpes de todos lados". (Roattino, 2018). 
y la autonomía del territorio en la región del norte del Cauca. Una palabra que, en primer lugar, asume valor pluralizado, dialéctico, comunitario: el texto se construye en un diálogo constante con las reflexiones, tensiones y acciones generadas desde las asambleas, las mingas ${ }^{12}$, los miembros de las comunidades, los movimientos y las asociaciones sociales (entre otras ACIN, CRIC, ONIC ${ }^{13}$ y Pueblos en Camino) y los "incómodos tejedores de consciencia" como Emanuel Rozental, estudioso de los procesos de resistencia del Cauca y activista en lucha desde el Cauca que ya en su artículo "Qué palabra camina la Minga" (2009), había propuesto el desafío y la necesidad de encontrar nuevas palabras para repensar imaginarios y derroteros de resistencia:

Nos corresponde reconocer, tejer y finalmente nombrar la palabra precisa, la verdadera, la colectiva, la necesaria, la sabia, para que esta se convierta en camino. Equivocar la palabra es negarse al discernimiento indispensable. Impedir el tejido paciente que la teje reconociendo y desarrollando el conflicto desde las diferencias y la reflexión, es permitir que se impongan, e imponer intereses particulares es encubrir, engañar, confundirse, dejarse llevar. Es errar el camino y condenar a los pueblos a su miseria desde la incandescencia confusa de lo pragmático, de lo jerárquico, de lo establecido y de lo inmediato. (Rozental, 2009, p. 56).

Almendra, en su sistemática investigación en busca de "encontrar la palabra perfecta" (Almendra, 2010), asume el reto de darle nuevos caminos a la palabra, aliviándola de dueños -"en la asamblea comunitaria todas y todos nos empoderamos de nuestra palabra y acción" (Almendra, 2017a, p. 97)- y colectivizándola en un "nosotroas" que se propone como respuesta a los intentos de privatización por parte de las fuerzas locales y transnacionales agresoras del territorio, cuyos proyectos de explotación no se limitan a la apropiación de cuerpos y lugares: aspiran, también, a una inclusiónexcluyente de imaginarios y lenguajes. La palabra se activa en este sentido como "personaje histórico común" (2017a, p. 97), al mismo tiempo producto y generador

12. Utilizando la definición de Almendra, como minga "se conoce al trabajo colectivo que se realiza en los territorios para alcanzar un objetivo individual o común que beneficie a las comunidades”. (2017a, p. 91).

13. Organización Nacional Indígena de Colombia. 
de asamblea y de acción comunitaria, y como forma de defensa en persistente contacto con los dos marcos estructurales, según la autora, de la lucha nasa en el Cauca: la resistencia y la autonomía.

Sin embargo, el discurso producidodesdeel texto engendra una estructura comunicativa más impactante que una simple palabra del resistir: es una palabra del di-sentir, es decir, de un sentir distinto o sentipensar (2017a, p. 279), indisolublemente conectado con Uma Kiwe (madre tierra) e inevitablemente distanciado de las significaciones asignadas al territorio por las estructuras de poder. Una palabra que provoca y desafía las necropolíticas en este contexto, identificables, en términos de Almendra, con "el proyecto de muerte (capitalismo) que nos fragmenta, captura y contiene" (2017a, p. 48): un proyecto ante el cual la comunicación de la autora se propone, utilizando a Foucault, como parrhesía: como profunda obligación de denuncia, absoluta necesidad de contar el hecho, como palabra "fundamental, esencial" (Foucault, 1982, p. 85). La escritura de Vilma Almendra se plantea como acción comunicativa en constante movimiento, posicionada en un lugar de enunciación incómodo y crítico - “yo ${ }^{14}$, indígena, nasa, misak, mujer" (2017a, p. 51) - en su rememoración de los momentos más contemporáneos de la resistencia nasa, cuyo epicentro se coloca en los 58 días de minga de resistencia social y comunitaria de 2008. Cumbre de la lucha desde el norte del Cauca en el siglo XXI, resultado de un proceso que se inició en septiembre de 2004 con el mandato indígena y popular realizado en Santiago de Cali, la imponente marcha hacia Bogotá de miles de indígenas se carga también de otro significado: el estallido de tensiones y contradicciones hasta entonces silenciadas, tanto externas (dinámicas relacionales con estructuras de poder de grupos guerrilleros) como internas (autoritarismos) a la resistencia, que darían vida a un lento y progresivo debilitamiento de los movimientos, en el delicado equilibrio "entre la emancipación y la captura”.

14. Es este fragmento el único donde aparece el pronombre "yo" en la escritura de Almendra, que en su proceso de colectivización de la palabra pluraliza constantemente el sujeto ("nosotroas") de la acción comunitaria: el "yo" utilizado aquí se presenta como una de "las identidades correspondientes [...] para ubicar a las y los lectores, pero también para desafiarnos constantemente a re-conocer lo existente y lo potencialmente realizable más allá de la identidad dada”. (Almendra, 2017a, p. 51). 
En su periodización de las distintas etapas de lucha, Almendra identifica justamente el año 2008 como núcleo de un giro desde una etapa de "emancipación" hacia un momento de "institucionalización del proceso e inserción a la lógica estatal” (2017a, p. 84). En las discordancias y construcciones antitéticas del pensamiento y de la acción de resistencia reveladas en la narrativa de la autora, nuevamente desempeńa un papel fundamental la palabra, la cual se hace cargo de las tensiones existentes y se ofrece como posible respuesta, a través de la conceptualización ${ }^{15}$ clave del palabrandar, que la autora piensa como una acción teórica y práctica que nos emergió cuando
[n]osotras y nosotros en medio de la muerte y el despojo, decidimos conscientemente asumir la comunicación otra, ponerle palabra al camino y caminar esa palabra: tener para ser palabrandando y no ser para tener mercantilizando. Desde allí entendimos que los medios que usamos son medios, pero no son el fin en sí mismos. Que ese fin está en nuestras manos y en la consciencia de colectividad, comunariedad y del arraigo a Mama Kiwe que tenemos como hijos e hijas de ella. (Almendra, 2017a, p. 50).

En este proceso de resignificación de la palabra para reactivar la acción, impulsado por Almendra a partir de la construcción colectiva del tejido de comunicación de la ACIN, en un primer momento, y con la creación de la iniciativa Pueblos en Camino desde el 2013, la escritora se conecta con los dos elementos más vulnerados por las políticas excluyentes del Gobierno colombiano y de las élites transnacionales: cuerpos y territorios. En su propuesta, ambas categorías quedan fortalecidas a través de una narrativa que no se presenta como simple autorrepresentación -en el acto de rememorar- sino como un camino vivo de defensa hacia la autonomía, con el objetivo de "dejar huella" en el camino comunitario (Almendra, 2017a, p. 50), de sembrar y desarrollar derroteros comunicativos que, al colocarse por fuera de la institucionalidad y de sus necropolíticas, logren convertirse en acción emancipatoria palabrandante, cuyo primer desafío debería traducirse en la capacidad de reconocer

15. Almendra se refiere a este acto de repensamiento de formas, sentidos y contenidos de las palabras con el término "reconcepcionalizar": "Más allá del concepto que muchas veces encarcela, queremos renombrar y resignificar nuestra propia concepción de comunicar, por eso no decimos 'reconceptualizar', más bien intentamos 'reconcepcionalizar'”. (Almendra, 2017b, p. 209). 
tensiones y contradicciones internas en los movimientos para la defensa de la autonomía territorial.

En medio de esta trayectoria, la palabra se posiciona al mismo tiempo dentro de Uma Kiwe y dentro de los cuerpos que han sido y están siendo explotados: si la tierra es "útero de las luchas" (2017a, p. 248) y en la enseńanza ancestral "indio sin tierra es indio muerto", la relación vida-cuerpo-tierra encuentra su más alta expresión en la palabra que camina y que hila caminos de desafíos a las necropolíticas. Si "nada es más material, más físico, más corporal que el ejercicio del poder" (Foucault, 1979, p. 105), es justamente desde el cuerpo que tiene que florecer la necesidad de impulsar el acto de disidencia a través de la palabra -que defiende el imaginario con el apoyo constante de la sabiduría ancestral-y del territorio, que defiende la vida de las explotaciones; de esta manera, en el palabrandar asumen una inmensa carga semántica expresiones verbales como ombligar (Almendra, 2017a, p. 50), conectar cuerpo y tierra en función de proteger el imaginario, así como surge en la narración que teje Almendra acerca del proyecto de liberación de la madre tierra: “esta acción, así no se haya logrado la tierra que se necesita para la reproducción material-espiritual de la vida plena, nos ayudó a seguir recuperando nuestro territorio del imaginario para arraigarlo y ombligarlo más a nuestra Uma Kiwe” (Almendra, 2017a, p. 113). Una construcción semántica que asume una profunda carga simbólica en su inevitable referencia a la tradición, propia del pueblo nasa, del sxab wes: la siembra al lado del fogón del cordón umbilical que se corta a las niñas y a los niños recién nacidos, en un primer contacto entre los cuerpos y la Uma Kiwe, para producir una conexión estable con las leyes de la madre tierra; un ritual radicado en la cultura ancestral nasa que se refleja en la lengua imaginada y practicada por Almendra.

Estos complejos y heterogéneos actos de re-semantización, deconstrucción y reformación de palabras y conceptos, que podemos encajar en el "proceso colectivo en disputa” (Almendra, 2017a, p. 191) definido como “comunicación otra” (p. 191), se producen como forma de contrastar las expresiones comunicativas que surgen desde las fuerzas gubernativas y transnacionales opresoras del territorio, capaces de absorber, privatizar y hacer propios imaginarios lexicales indígenas, con el objetivo de absorber, privatizar y hacer propias las comunidades en lucha. En este sentido, los actores estatales se identifican con la categoría propuesta por Mbembe de 
"máquina de guerra", que tiene los rasgos de una organización política y de una sociedad mercantil. Actúa mediante capturas y depredaciones y puede alcanzar enormes beneficios. Para permitir la exportación de recursos naturales localizados en el territorio que controlan, las máquinas de guerra forjan conexiones directas con redes transnacionales (Mbembe, 2006, p. 59).

En este acto de absorbimiento e inclusión de los imaginarios, las estructuras opresoras generan expresiones comunicativas definibles, manteniendo los modos interpretativos de Achille Mbembe, como formas de necrolenguaje producidas por el "necropoder" (2006, p. 45), en una situación común a diferentes contextos de relación Estado-comunidades indígenas en América Latina; piénsese en el caso de la apropiación del imaginario indígena andino del sumak kawsay', traducido como "buen vivir" en la Constitución de 2008 por parte del Estado ecuatoriano. Un proceso que Catherine Walsh analiza a partir de las problematizaciones del lenguaje adoptado por el Gobierno:

Como tal, el nuevo paradigma (¿paradogma?) del desarrollo humano [...] sugiere el funcionamiento continuo en América Latina de la lógica multicultural del capitalismo neoliberal y de su capacidad para condicionar los modos de pensar y conformarse a un sentido común que legitime las máquinas del poder, lo que hace cada vez más difícil buscar alternativas (Torres, citado en Sverdlick, 2002). En este sentido, y a pesar de su lenguaje "holístico" e "integral", está vinculado al proseguimiento de la imposición colonial moderna occidental. La idea misma del desarrollo es un concepto y una palabra que no existe en las cosmovisiones, en las categorías conceptuales y en los lenguajes de las comunidades indígenas ${ }^{16}$. (Walsh, 2010, p. 17).

En este mismo orden de apreciaciones -proyectos de aparente inclusión que se revelan excluyentes-, en el caso caucano el necrolenguaje se manifiesta en las distorsionadas denominaciones de operaciones políticas de muerte como el Plan Colombia para la paz, de hecho un plan de "ocupación integral y desmantelamiento

16. Traducción propia. 
de legendarios procesos de lucha indígena” (Almendra, 2017a, p. 79) que desde su implementación bajo el Gobierno de Andrés Pastrana Arango continúa afectando de manera contundente (entre otros) los resguardos nasa del norte del Cauca. De igual manera, detrás de las calificaciones de Familias Guardabosques (2002 - dentro de la activación del plan de sustitución de cultivos ilícitos) o Más Familias en Acción (2006 - programa de asistencia para familias con bajos recursos) se han escondido, según Almendra, proyectos de muerte, explotación y despojo, que han contribuido a la privatización de tiempos, espacios, imaginarios, territorios y cuerpos, también a causa de las elecciones emprendidas por las comunidades:

Cuando hay un horizonte de lucha claro que se camina territorialmente, las respuestas comunitarias frente a la dominación van a desbordarla, pero cuando este horizonte se empieza a confundir con las acciones que lo alimentan, las decisiones comunitarias tienden a debilitarse y fragmentarse. Esto fue lo que nos pasó cuando los diversos cabildos indígenas del norte del Cauca, en la última década empezaron a aceptar uno a uno, sin previa consulta interna ni decisión clara colectivizada, la entrada de Más Familias en Acción, otro programa de asistencia enfocado a madres de familia y niños "vulnerables", quienes reciben un apoyo económico cada dos meses. Este programa ha logrado disminuir la participación en los espacios de decisión y movilización -aprovechando las necesidades económicas de las familias de las comunidades y la debilidad de la organización indígena, pues las familias prefieren hacer largas horas de fila para recibir un poco de dinero, que sentarse a "perder el tiempo en largas filas donde solo recibirán un sancocho, sopa típica de la asamblea-. Además, no es fortuito que institucionalmente programen la entrega de estos recursos cuando hay asambleas o congresos, así ha pasado en varios resguardos indígenas. No es difícil ver que la intención es disminuir la asistencia y participación a los espacios de decisión y acción colectivos que alimentan la territorialidad. (Almendra, 2017a, pp.167-168).

En un párrafo que muestra las debilidades, dificultades y contradicciones de la lucha indígena en el Cauca, Almendra sintetiza los sentidos de la necesitad de su palabrandar: desenmascarar los supuestos proyectos de inclusión que agazapan nuevos intentos de apoderamiento del territorio, por medio de políticas de explotación que 
se construyen a partir de prácticas discursivas de necrolenguajes; proponer, entonces, derroteros de resistencia distintos, a partir de una renovada concepción del pensar, de formalizar los contenidos, que puede volverse poderosa a través de una textura de redes entre las grandes luchas territoriales locales, en un camino conjunto que no pertenece solamente al Cauca: se mueve "desde el Cauca", en conexión con todas las Uma Kiwe del planeta: "Nuke Mapu le llaman en idioma mapuche, Uma Kiwe para el pueblo nasa, Meye Dobo le nombran en la comarca panameña Ngäbe Buglé, Nishnabe Aki para los ojibway o chippewa, Nana Echeri en idioma purhépecha” (Almendra, 2017a, p. 280). Un desafío discursivo, donde el acto comunicativo se propone como motor de la práctica de resistencia, tanto hacia el interior de la comunidad como hacia la generación de redes que se entrelazan con las fronteras comunitarias, en una búsqueda constante de renovación y protección, en una práctica mediante la cual, en palabras de Arturo Escobar, "las personas construyen lugares [...] en redes translocales" (Escobar, 2010, p. 141).

\section{ConClusiones}

Las comunidades indígenas nasa en los territorios del norte del Cauca se encuentran hace siglos en estado de resistencia ante innumerables intentos de invasión, explotación y violación de cuerpos y territorios, dentro de procesos que en época poscolonial se definen, según Achille Mbembe, como prácticas de necropoder. Sin embargo, el pueblo nasa ha sido capaz, en el curso de los siglos, de rechazar los continuos ataques por parte del Estado nacional, de élites transnacionales, de terratenientes y de variados grupos armados con el objetivo de provocar una condición extendida de marginación y exclusión poblacional en la región. Durante las últimas décadas, dicho proceso de resistencia ha sido catalizado y valorado a través de la activación de una memoria cultural que ha permitido la reactualización y la consolidación de mitos, tejidos y proyectos de lucha. En la configuración de estas dinámicas ha desempeñado un papel relevante la difusión de la palabra escrita, particularmente a partir de los años setenta, con el surgimiento del CRIC y la publicación de la obra de Manuel Quintín Lame. En este marco, el texto Entre la emancipación y la captura (2017) de Vilma Almendra se encarga de producir una profunda reflexión sobre las posibilidades, los objetivos y las necesidades de una nueva forma de pensar el rol 
y la naturaleza de la palabra como medio de acción determinante en el proceso de resistencia. En una operación textual que no se limita a una reelaboración teórica de la palabra de resistencia indígena, Almendra logra también un ejercicio expresivo fundacional de una práctica discursiva experimental e innovadora: el palabrandar como derrotero de acción y comunicación, fundado en una expresión libre de dueños y en un reposicionamiento semántico de la palabra escrita indígena hacia un lugar de enunciación comunitario y radicado en la Uma Kiwe.

En un contexto sociohistórico en el cual las necropolíticas se han convertido en prácticas cotidianas y donde los intentos de generación de sujetos-objetos relegados a homines sacri ha llegado al punto de concebir el propósito de producir falsos positivos hasta durante la minga de resistencia social y comunitaria ${ }^{17}$, la enorme apuesta de Almendra y de la entera comunidad de "incómodos tejedores de consciencias" que se mueve desde el Cauca, se encuentra en una respuesta activa, dialógica y colectiva a la marginación impuesta tanto mediante la acción política como a través de los sistemas discursivos colonizadores de los centros de poder; una respuesta que se funda, ante todo, en una "comunicación otra", impulsada a partir del repensamiento del individuo como sujeto comunitario y "palabrandante", resistente al necrolenguaje y no identificable como sujeto al margen.

\section{REFERENCIAS}

Agamben, G. (1998). Homo Sacer. El poder soberano y la nuda vida. Valencia, España: Pre-Textos.

Agamben, G. (2002). Lo abierto. El hombre y el animal. Buenos Aires, Argentina: Adriana Hidalgo Editora.

17. Refiere este caso al episodio, citado en el texto de Almendra, de Jairo Danilo Chaparral: "soldado activo que se había infiltrado con material militar en nuestra movilización con la misión de sembrar un falso positivo en la marcha”. (Almendra, 2017a, p. 149). 
Almendra, V. (2010). Encontrar la palabra perfecta: experiencia del tejido de comunicación del pueblo nasa en Colombia. Cali, Colombia: Universidad Autónoma de Occidente/Dirección de Investigaciones y Desarrollo Tecnológico,

Almendra, V. (2017a). Entre la emancipación y la captura. Memorias y caminos desde la lucha nasa en Colombia. México D. F., México: Grietas Editores.

Almendra, V. (2017b). Palabrandando: entre el despojo y la dignidad. En C. Walsh (ed.), Pedagogias decoloniales: prácticas insurgentes de resistir, (re)existir y (re)vivir, Tomo II. Quito, Ecuador: Ediciones Abya-Yala.

Alves, J. A. (2011). Topografias da Violencia: necropoder e governamentalidade espacial em Sao Paulo. Revista do Departamento de Geografia, 22, 14-37. DOI: https://doi. org/10.7154/RDG.2011.0022.0006

Ávila, K. (2018). Estado de excepción y necropolítica como marco de los operativos policiales en Venezuela. Revista Critica Penal y Poder, 15, 180-214.

Bello Ramírez, J. A., y Parra Gallego, G. (2016). Cárceles de la muerte: necropolítica y sistema carcelario en Colombia. Universitas Humanistica, 82, 365-391. DOI https://revistas. javeriana.edu.co/index.php/univhumanistica/article/view/13065

Cardoso Hilário, L. (2016). Da biopolítica à necropolítica: variaçôes foucaultianas na periferia do capitalismo. Sapere aude, 7(13), 194-210. DOI: https://doi. org/10.5752/P.2177-6342.2016v7n13p194

Consejo Regional Indígena del Cauca, Programa de Educación Bilingüe e Intercultural CRIC-PEBI. (2004). ¿Quépasaría si la escuela...?30 años de construcción de una educación propia. Popayán, Colombia: Editorial Fuego Azul.

Deleuze, G., y Guattari, F. (1980). Mil plateaux (capitalisme et schizophrénie). París, Francia: Les Editions de Minuit. 
Escobar, A. (2010). Una minga para el postdesarrollo: lugar, medio ambiente y movimientos sociales en las transformaciones globales. Lima, Perú: Universidad Nacional Mayor de San Marcos, Fondo Editorial de la Facultad de Ciencias Sociales.

Estévez, A. (2018). El dispositivo necropolítico de producción y administración de la migración forzada en la frontera Estados Unidos-México. Estudios fronterizos, 19, 1-18. https://dx.doi.org/10.21670/ref.1810010

Foucault, M. (1979). Microfísica del poder. Madrid, España: La Piqueta.

Foucault, M. (1982). El gobierno de sí y de los otros. Buenos Aires, Argentina: Fondo de Cultura Económica.

Foucault, M. (1992). Genealogía del racismo. De la guerra de las razas al racismo de Estado. La Plata, Argentina: Editorial Altamira.

Fuentes Díaz, A. (ed.). (2012). Necropolitica: violencia y excepción en América Latina. México D. F., México: Benemérita Universidad Autónoma de Puebla.

Gnecco, C. (ed.) (2004). Manuel Quintín Lame. Los pensamientos del indio que se educó dentro de las selvas colombianas. Popayán, Colombia: Editorial Universidad del Cauca.

Mbembe, A. (2006). Necropolítica. Madrid, España: Editorial Melusina.

Patiño Prieto, J. C. (2008). Quintín Lame: la escritura indígena entre lo poético, lo críptico y lo telúrico. En Literatura, prácticas críticas y transformación cultural. Jalla Bogotá, Tomo II. Bogotá D. C., Colombia: Ediciones Uniandes, Editorial Pontificia Universidad Javeriana y Ediciones Universidad Nacional de Colombia.

Peñaranda Supelano, D. R. (2012). Nuestra vida ha sido nuestra lucha. Resistencia y memoria en el Cauca indígena. Bogotá D. C., Colombia: Centro de Memoria Histórica.

Peñaranda Supelano, D. R. (2015). Guerra propia, guerra ajena. Conflictos armados y reconstrucción identitaria en los Andes colombianos: el Movimiento Armado Quintín Lame. 
Bogotá D. C., Colombia: Centro Nacional de Memoria Histórica, Universidad Nacional de Colombia.

Roattino, E. (2018). Entrevista grabada el 25 noviembre de 2018 en la Parroquia de Toribío (Cauca).

Rozental, E. (2009). ¿Qué palabra camina la Minga? Deslinde. Revista Cedetrabajo, 45, 50 59. Recuperado de https://deslinde.co/que-palabra-camina-la-minga/

Ulcué Chocué, Á. (1983). Documento acerca de los objetivos generales del "Centro Indigenista Toribío Cauca” emanado en la Parroquia San Juan Bautista de Toribío (Cauca) el 25 de febrero de 1983. Consultado en la Parroquia de San Juan Bautista de Toribío (Cauca) el 25 de noviembre de 2018.

Valencia Triana, S. (2017). Capitalismo gore: narcomáquina y performance de género. En A. De Santiago Guzmán, E. Caballero Borja y G. González Ortuño (eds.), Mujeres intelectuales. Feminismos y liberación en América Latina y el Caribe (pp. 371-388). Buenos Aires, Argentina: Clacso.

Walsh, C. (2010). Development as Buen Vivir: Institutional arrangements and (de)colonial entaglements. Development, 53(1), 15-21.

Wolf, E. (1972). Las luchas campesinas del siglo XX. México D. F., México: Siglo Veintiuno Editores. 